\title{
APLIKASI SMART HOME NODE MCU IOT UNTUK BLYNK
}

\author{
${ }^{1}$ Marina Artiyasa, ${ }^{2}$ Aidah Nita Rostini, ${ }^{3}$ Edwinanto, ${ }^{4}$ Anggy Pradifta Junfithrana, \\ ${ }^{1,2,3,4}$ Program Studi Teknik Elektro \\ $1,2,3,4$ Universitas Nusa Putra \\ ${ }^{1,2,3,4}$ Jl. Raya Cibolong Kaler No.21 Kab. Sukabumi \\ 1'marina.artiyasa@nusaputra.ac.id, ${ }^{2}$ anr430@gmail.com, ${ }^{3}$ edwinanto@nusaputra.ac.id, \\ ${ }^{4}$ mr.pradiftha@nusaputra.ac.id \\ Korespendensi: ${ }^{1}$ marina.artiyasa@nusaputra.ac.id
}

\begin{abstract}
ABSTRAK
Rumah pintar merupakan inovasi Internet of Thing (IOT), Dimana semua benda atau perabotan rumah sehari-hari yang akrab dengan masyarakat "dioptimalkan" karena integrasi teknologi dalam bentuk chip serba bisanya,Dalam hal smart home, internetof thing akan hadir dalam rupa barang-barang yang bisa di temui di rumah orang kebanyakan. Aplikasi dari system smart home berbasis (IoT) Internet Of Thing ini menggunakan modul NodeMCU ESP8266 sebagai microcontroller dan aplikasi android Blynk sebagai alat pengendali ataupun monitoring. System ini terdiri dari pengendali lampu, Moitoring sensor suhu , pendeteksi pergerakan di suatu ruangan, dan pendeteksi kebocoran gas. Terdapat tiga sensor yang digunakan yaitu sensor PIR untuk mendeteksi adanya pergerakan, sensor MQ2 untuk mendeteksi adanya kebocoran gas, Dan sensor LM35 untuk monitoring suhu. Selain itu dalam rancangan sistem ini juga memakai relay yang digunakan sebagai penghubung lampu dengan system. Dari hasil pengujian dan analisa pengendalian peralatan elektronik pada smart home ini beroprasi sesuai perintah yang di berikan. Adapun beberapa uji coba yang di lakukan adalah uji coba jarak terjauh menghidupkan lampu dan jarak terjauhnya adalah 35 meter, Untuk jarak terjauh deteksi sensor PIR adalah 8 meter, dan untuk jarak terjauh sensor MQ2 5 meter, percobaan penghitung tegangan relay dengan lampu saat lampu keaadaan hidup dan mati, Dan sensor PIR saat mendeteksi pergerakan dan tidak. Selama system terkoneksi dengan jaringan internet secara stabil dan continue tidak akan terjadi kendala pada system smart home berbasis IoT (Internet Of Things)
\end{abstract}

Kata Kunci: Buzzer, LM35, Node MCU, Relay 2 Channel dan Sensor PIR.

\begin{abstract}
Smart home is an innovation of The Internet Of Thing (IOT), where all objects or everyday home furnishings that are familiar with the community "optimized" because of the integration of technology in the form of versatile chips, In terms of smart home, internetof thing will be present in the form of items that can be found in the home of most people. This application from internet of thing smart home system (IoT) uses NodeMCU ESP8266 module as microcontroller and Blynk android application as controller or monitoring tool. This system consists of lamp controller, Moitoring temperature sensor, movement detection in a room, and gas leak detector. There are three sensors used namely PIR sensor to detect movement, MQ2 sensor to detect gas leakage, and LM35 sensor for temperature monitoring. In addition, in the design of this system also uses a relay that is used as a lamp connector with the system. From the results of testing and analysis of electronic equipment control in this smart home is based on the orders given. As for some of the trials conducted is the trial of the furthest distance turn on the lamp and the furthest distance is 35 meters, For the furthest distance detection pir sensor is 8 meters, and for the furthest distance $M Q 2$ sensor 5 meters, experiment relay voltage counter with lights when the lights are on and off, and PIR sensors when detecting movement and not. As long as the system is connected to the internet network steadily and continue there will be no constraints on the Smart Home system based on IoT (Internet Of Things).
\end{abstract}

Keywords: Buzzer, LM35, NODE MCU, Relay 2 Channel and PIR Sensor. 


\subsection{Latar Belakang}

\section{PENDAHULUAN}

Meningkatkan implementasi teknologi dan semakin kompleknya teknologi sekarang ini,berbagai macam tempat tinggal yang umum seperti rumah dan apartemen memiliki kelebihan dan kekuranan masing-masing. Apartemen yang memiliki teknologi yang lebih baik seperti menggunakan identitas yang menggunakan chip untuk membuka pintu tentu membutuhkan biaya yang lebih mahal, Sedangkan rumah yang memiliki teknologi sederhana mempunyai keuntungan yaitu biaya yang lebih murah [1].

Rumah pintar sering dikenal Smart Home merupakan sebuah rumah yang memiliki definisi seperti tempat tinggal,yang dapat bekerja secara otomatis yang dapat bekerja seakan-akan seperti manusia. Sistem rumah cerdas (Smart Home) Adalah system aplikasi yang merupakan gabungan antara teknologi dan pelayanan yang di khususkan pada lingkungan rumah dengan fungsi tertentu yang bertujuan meningkatkan efesiensi, kenyamanan dan keamanan penghuninya. Sistem Rumah Pintar biasanya terdiri dari perangkat kontrol,monitoring dan otomatisasi beberapa perangkat atau peralatan rumah yang dapat di akses melalui sebuah computer [2]. Sistem Smart Home dengan berbagai fasilitasnya, akan memberikan ke amanan dan kenyamanan bagi pemilik rumah dan orang-orang yang tinggal di dalamnya,karena dapat memudahkan pekerjaan agar menjadi lebih cepat,efektif dan efisien [3].

Sering kali aktivitas dirumah yang menggunakan peralatan dalam kehidupan seharihari menjadi permasalahan dan mengakibatkan kurang efesien dalam penggunaannya untuk beraktifita, seperti seseorang yang sibuk dengan aktifitasnya,sehingga lupa mematikan listrik yang sedang di gunakan dan bisa saja mengakibatkan kebakaran.

\subsection{Penelitian Terkait}

\section{TINJAUAN PUSTAKA}

Rijal Permana dengan judul "Perancangan sistem keamanan dan kontrol smart home berbasis internet of things" sistem kontrol dengan NodeMCU berfungsi dengan baik saat tombol di tekan pada aplikasi android yang telah dibuat dengan presentase keberhasilan $100 \%$ dengan delay rata rata tidak lebih dari 3 detik untuk semua pengontrolan. Hal ini dapat dilihat dari pengujian sistem kontrol yang dilakukan sebanyak 30 kali [4].

Abidin, Z. dengan judul "Sistem Keamanan Dan Monitoring Rumah Pintar Secara Online Menggunakan Perangkat Mobile - Universitas Komputer Indonesia (2016)" Perancangan aplikasi ini merupakan salah satu bagian dalam pengembangan dari sistem keamanan dan monitoring rumah pintar secara online, yaitu untuk memonitor rumah dalam jarak jauh. Menggunakan Node MCU, sensor PIR (Passive Infra red) dan raspberry [5].

Nurul Hidayati Lusita Dewi dengan judul "Prototype smart home dengan modul nodemcu esp8266berbasis internet of things" Mengoptimalkan power control consumption modul NodeMCU ESP8266 untuk lebih dikembangkan pada aplikasi teknologi berbasis wireless, mengingat arus teknologi sekarang mengutamakan low cost namun berdayaguna [1].

Juwariyah dengan judul "Perancangan Sistem Deteksi Dini Pencegah Kebakaran Rumah Brbasis Esp8266 dan Blynk" pencegah kebakaran berbasis Arduino Mega2560, sensor gas MQ6, sensor api, ESP8266, router WiFi dan aplikasi Blynk di smartphone mampu memantau adanya potensi kebakaran oleh adanya api. Melalui sistem cloud yaitu layanan Blynk cloud dan koneksi WiFi berbasis ESP8266 sistem mampu memberikan informasi jarak jauh kondisi akan keberadaan api dan gas secara real time melalui GUI aplikasi Blynk di smartphone android. Hasil penelitian ini diharapkan dapat menjadi salah satu referensi penerapan IOT (Internet of Things) khususnya rancangan smart home [6].

\subsection{Komponen Pendukung}

\section{Node MCU}

NodeMCU adalah sebuah platform IoT yang bersifat open source. Terdiri dari perangkat keras berupa System On Chip ESP8266 dari ESP8266 buatan Espressif System, juga firmware yang digunakan, yang menggunakan bahasa pemrograman scripting Lua. Istilah NodeMCU secara default sebenarnya mengacu pada firmware yang digunakan dari pada 
perangkat keras development kit. NodeMCU bisa dianalogikan sebagai board arduino-nya ESP8266. Dalam seri tutorial ESP8266 embeddednesia pernah membahas bagaimana memprogram ESP8266 sedikit merepotkan karena diperlukan beberapa teknik wiring serta tambahan modul USB to serial untuk mengunduh program. Namun NodeMCU telah me-packageESP8266 ke dalam sebuah board yang kompak dengan berbagai fitur layaknya mikrokontroler + kapabilitas akses terhadap Wifi juga chip komunikasi USB to serial. Sehingga untuk memprogramnya hanya diperlukan ekstensi kabel data USB persis yang digunakan sebagai kabel data dan kabel charging smartphone Android.

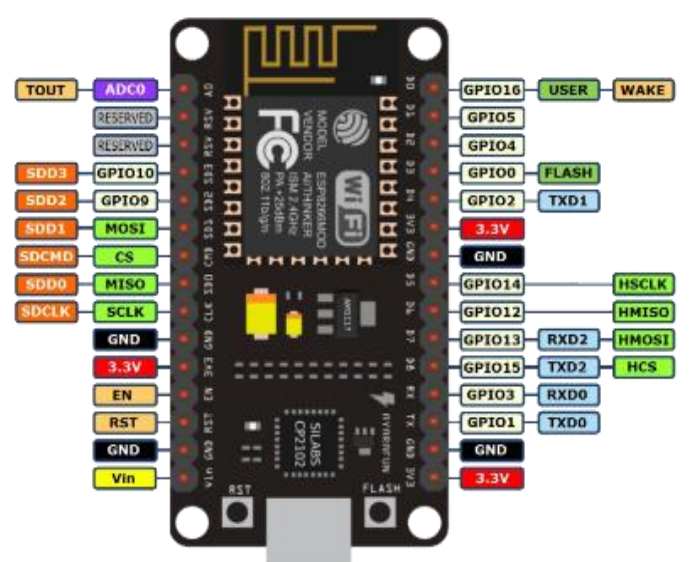

Gambar 1. Node MCU

2. Relay

Relay adalah suatu peranti yang bekerja berdasarkan elektromagnetik untuk menggerakan sejumlah kontaktor yang tersusun atau sebuah saklar elektronis yang dapat dikendalikan dari rangkaian elektronik lainnya dengan memanfaatkan tenaga listrik sebagai sumber energinya. Kontaktor akan tertutup (menyala) atau terbuka (mati) karena efek induksi magnet yang dihasilkan kumparan (induktor) ketika dialiri arus listrik. Berbeda dengan saklar, pergerakan kontaktor (on atau off) dilakukan manual tanpa perlu arus listrik.

\section{Sensor PIR}

Sensor PIR (Passive Infrared Receiver) adalah sebuah sensor yang biasa digunakan untuk mendeteksi keberadaan manusia. Aplikasi ini biasa digunakan untuk system alarm pada rumah-rumah atau perkantoran. Sensor PIR adalah sebuah sensor yang menangkap pancaran sinyal inframerah yang dikeluarkan oleh tubuh manusia maupun hewan. Sensor PIR dapat merespon perubahan- perubahan pancaran sinyal inframerah yang dipancarkan oleh tubuh manusia. Keadaan ruangan dengan perubahan temperatur pada manusia dalam suatu ruangan menjadi nilai awal (set point) yang menjadi acuan dalam sistem pengontrolan. Perubahan temperatur pada manusia dalam ruangan akan terdeteksi oleh Sensor PIR. Dikatakan PIR (Passive Infrared Receiver) karena sensor ini hanya mengenali lingkungan tanpa adanya energi yang harus dipancarkan. PIR merupakan kombinasi sebuah kristal pyroelectric, filter dan lensa Fresnel.

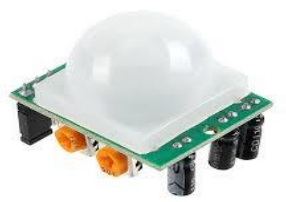

\section{Gambar 2. Sensor PIR}

4. Aplikasi Blynk

Blynk adalah platform untuk IOS atau ANDROID yang digunakan untuk mengendalikan module arduino, Rasbery $\mathrm{Pi}$, Wemos dan module sejenisnya melalui internet. Aplikasi ini sangat mudah digunakan bagi orang yang masih awam. Aplikasi ini memiliki banyak fitur yang memudahkan pengguna dalam memakainya. Cara membuat projek di aplikasi ini sangat gampang, tidak sampai 5 menit yaitu dengan cara drag and drop. Blynk tidak terkait dengan module atau papan tertentu. Dari aplikasi inilah kita dapat mengontrol apapun dari jarak jauh dimana pun kita berada dengan catatan terhubung dengan internet. Hal inilah yang disebut dengan IOT (Internet Of Things).

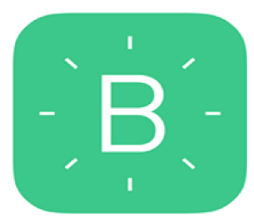

Gambar 3. Aplikasi Blynk 


\section{Sensor Suhu LM35}

Sensor suhu LM35 adalah komponen elektronika yang memiliki fungsi untuk mengubah besaran suhu menjadi besaran listrik dalam bentuk tegangan. Sensor Suhu LM35 yang dipakai dalam penelitian ini berupa komponen elektronika elektronika yang diproduksi oleh National Semiconductor. LM35 memiliki keakuratan tinggi dan kemudahan perancangan jika dibandingkan dengan sensor suhu yang lain, LM35 juga mempunyai keluaran impedansi yang rendah dan linieritas yang tinggi sehingga dapat dengan mudah dihubungkan dengan rangkaian kendali khusus serta tidak memerlukan penyetelan lanjutan.

Meskipun tegangan sensor ini dapat mencapai 30 volt akan tetapi yang diberikan kesensor adalah sebesar 5 volt, sehingga dapat digunakan dengan catu daya tunggal dengan ketentuan bahwa LM35 hanya membutuhkan arus sebesar $60 \mu \mathrm{A}$ hal ini berarti LM35 mempunyai kemampuan menghasilkan panas (self-heating) dari sensor yang dapat menyebabkan kesalahan pembacaan yang rendah yaitu kurang dari 0,5 ${ }^{\circ} \mathrm{C}$ pada suhu $25^{\circ} \mathrm{C}$.

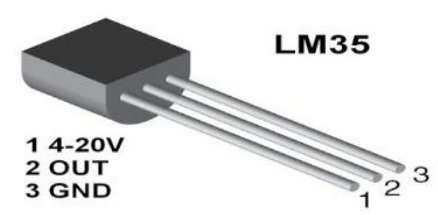

Gambar 4. Sensor LM35

\section{Sensor MQ2}

Sensor MQ-2 adalah salah satu sensor yang sensitif terhadap asap rokok. Bahan utama sensor ini adalah $\mathrm{SnO} 2$ dengan konduktifitas rendah pada udara bersih. Jika terdapat kebocoran gas konduktifitas sensor menjadi lebih tinggi, setiap kenaikan konsentrasi gas maka konduktifitas sensor juga naik. MQ-2 sensitif terhadap gas LPG, Propana, Hidrogen, Karbon Monoksida, Metana dan Alkohol serta gas mudah terbakar diudara lainnya.

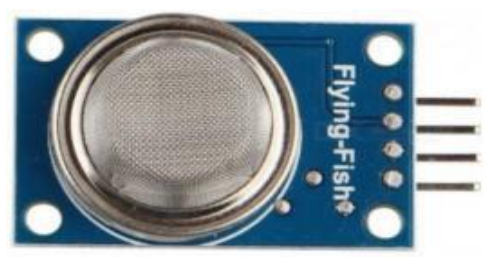

Gambar 5. Sensor MQ2

\section{METODOLOGI PENELITIAN}

\subsection{Perancangan Umum Sistem}

Setelah melakukan penelitian kemudian memulai tahap pembuatan alat, alat di cek satu persatu terlebih dahulu kemudian di rangkai hingga alat bisa berjalan.

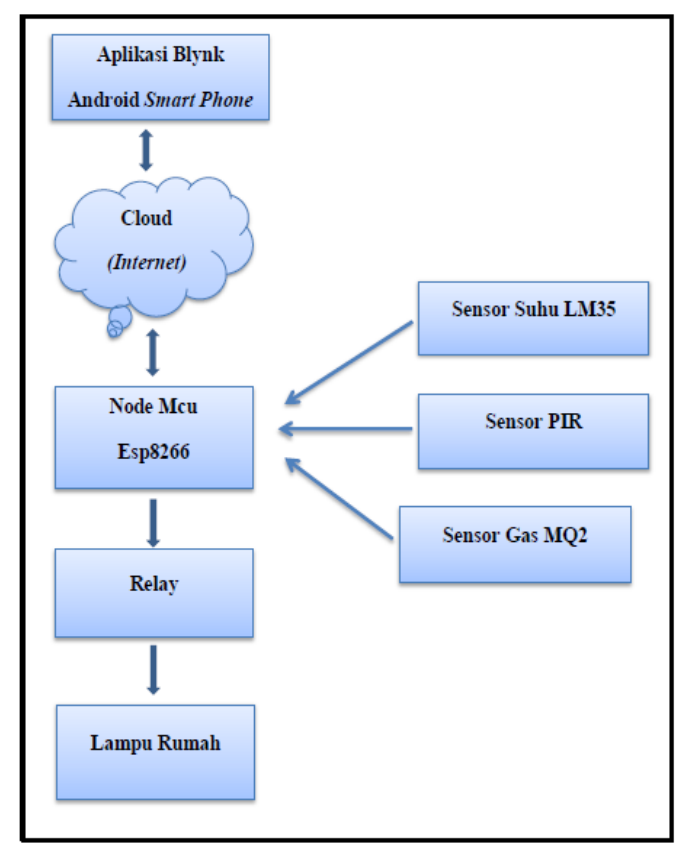

\section{Gambar 6. Blok Perancangan Smart Home}

Gambar 6. merupakan blok diagram perancangan Smart Home yang inputannya terdiri dari sensor suhu LM35, sensor MQ2,sensor PIR dan aplikasi blynk (Tombol),Dan untuk Prosenya ada node mcu,dan untuk outputnya Lampu,relay,buzzer dan blynk.

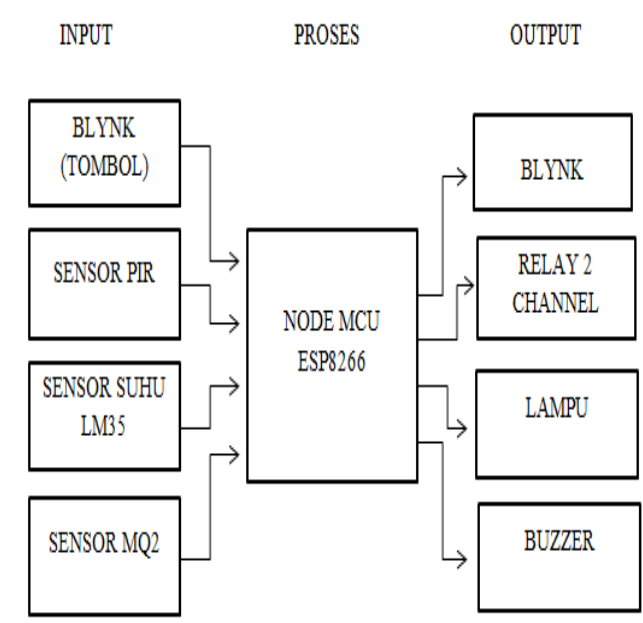

Gambar 7. Blok Proses Smart Home 
Gambar 7. Menjelaskan blok proses pembuatan smart home,terdiri dari input,proses dan output,untuk input terdiri dari sensor MQ2,sensor suhu LM35, sensor PIR, dan Blynk untuk tombol menghidupkan lampu,dan untuk perosesnya disini menggunakan node MCU ESP8266,dan untuk outpunya ada buzzer,Relay 2 channel,lampu dan aplikasi smartphone yaitu blynk.

\subsection{Perancangan dan Perakitan Alat}

Adapun konfigurasi sensor pada sistem yang digunakan untuk mendapatkan bebrapa informasi dapat dilihat pada Gambar 8. dibawah ini.

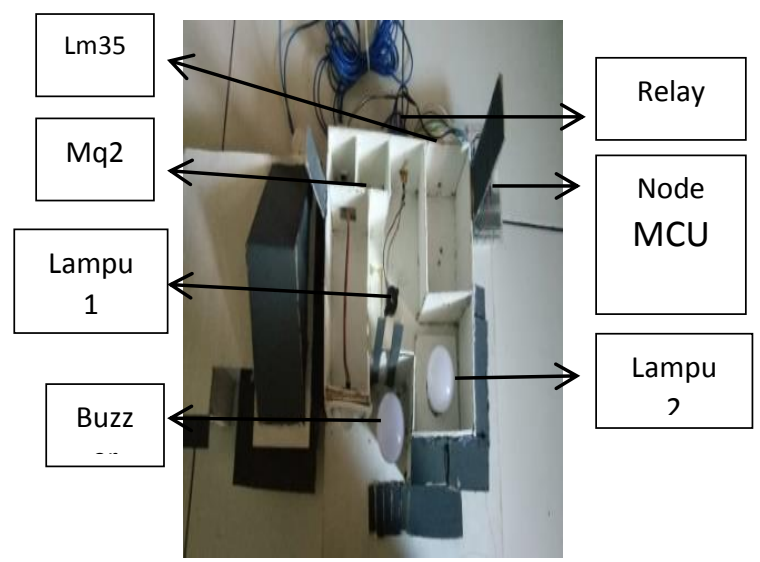

Gambar 8. Konfigurasi sensor

\subsection{Perancangan Antarmuka Aplikasi}

Perancangan antarmuka aplikasi ini merupakan bagian yang sangat penting dalam perancangan secara keseluruhan, dikarenakan antarmuka ini adalah bagian yang paling sering digunakan oleh pengguna untuk menjalankan fungsi-fungsi yang ada pada sistem ini. Antarmuka aplikasi ini dibuat dan berfungsi untuk monitoring dan remote pada sensor yang terpasang dengan mikrokontroller Node MCU. Untuk perancangan antarmuka aplikasi dapat dilihat pada Gambar 9. dibawah ini.

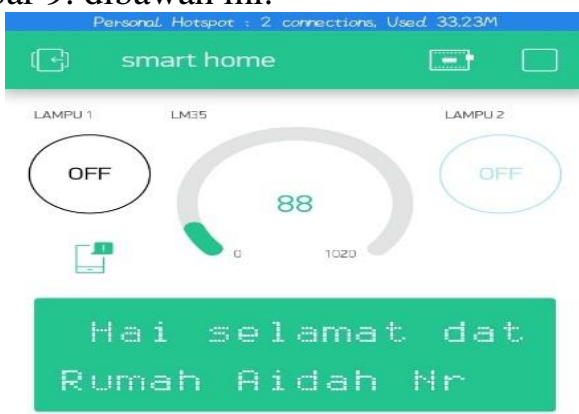

Gambar 9. Antar Muka Aplikasi Pengujian

\section{HASIL DAN PEMBAHASAN}

\subsection{Uji Kontrol Lampu dengan Relay}

Pengujian dilakukan dengan menekan widget button on/off pada aplikasi blynk di android smart phone masing-masing untuk lampu. Hal ini dilakukan setelah sistem dinyalakan dan tersambung pada koneksi internet WiFi. Jika sewaktu-waktu koneksi internet terputus atau sinyal dam keadaan buruk, maka hal itu juga mempengaruhi kinerja sistem. Pengujian pada Relay dan Lampu ini bertujuan untuk mengatahui apakah berjalan dengan baik dan maksimal, memberikan tegangan pada setiap rangkayan dengan kombinasi pemerograman yang benar.Relay diletakan di bagian tertutup dan lampu di letakkan dibagian terbuka.

Dan untuk percobaan selanjutnya adalah untuk mengetahui jarak untuk bisa mengakses aplikasi blynk untuk mengontrol lampu,dan hasil uji cobanya adalah sebagai berikut :

Tabel 1. Percobaan menghidupkan lampu

\begin{tabular}{|c|c|c|c|c|c|c|c|c|c|c|c|}
\hline \multirow{2}{*}{$\begin{array}{c}\text { Jarak } \\
\text { Objek } \\
\text { Meter })\end{array}$} & \multicolumn{7}{|c|}{ Hasil Pengujian } & \multirow{2}{*}{$\begin{array}{c}\text { Presentase } \\
\text { Keberhasilan }\end{array}$} \\
\cline { 2 - 10 } & 1 & 2 & 3 & 4 & 5 & 6 & 7 & 8 & 9 & 10 & \\
\hline 1 & $\mathrm{~S}$ & $\mathrm{~S}$ & $\mathrm{~S}$ & $\mathrm{~S}$ & $\mathrm{~S}$ & $\mathrm{~S}$ & $\mathrm{~S}$ & $\mathrm{~S}$ & $\mathrm{~S}$ & $\mathrm{~S}$ & $100 \%$ \\
\hline 2 & $\mathrm{~S}$ & $\mathrm{~S}$ & $\mathrm{~S}$ & $\mathrm{~S}$ & $\mathrm{~S}$ & $\mathrm{~S}$ & $\mathrm{~S}$ & $\mathrm{~S}$ & $\mathrm{~S}$ & $\mathrm{~S}$ & $100 \%$ \\
\hline 3 & $\mathrm{~S}$ & $\mathrm{~S}$ & $\mathrm{~S}$ & $\mathrm{~S}$ & $\mathrm{~S}$ & $\mathrm{~S}$ & $\mathrm{~S}$ & $\mathrm{~S}$ & $\mathrm{~S}$ & $\mathrm{~S}$ & $100 \%$ \\
\hline 5 & $\mathrm{~S}$ & $\mathrm{~S}$ & $\mathrm{~S}$ & $\mathrm{~S}$ & $\mathrm{~S}$ & $\mathrm{~S}$ & $\mathrm{~S}$ & $\mathrm{~S}$ & $\mathrm{~S}$ & $\mathrm{~S}$ & $100 \%$ \\
\hline 6 & $\mathrm{~S}$ & $\mathrm{~S}$ & $\mathrm{~S}$ & $\mathrm{~S}$ & $\mathrm{~S}$ & $\mathrm{~S}$ & $\mathrm{~S}$ & $\mathrm{~S}$ & $\mathrm{~S}$ & $\mathrm{~S}$ & $100 \%$ \\
\hline 7 & $\mathrm{~S}$ & $\mathrm{~S}$ & $\mathrm{~T}$ & $\mathrm{~S}$ & $\mathrm{~S}$ & $\mathrm{~S}$ & $\mathrm{~S}$ & $\mathrm{~T}$ & $\mathrm{~T}$ & $\mathrm{~S}$ & $70 \%$ \\
\hline 8 & $\mathrm{~S}$ & $\mathrm{~T}$ & $\mathrm{~S}$ & $\mathrm{~S}$ & $\mathrm{~T}$ & $\mathrm{~T}$ & $\mathrm{~S}$ & $\mathrm{~T}$ & $\mathrm{~S}$ & $\mathrm{~S}$ & $50 \%$ \\
\hline 9 & $\mathrm{~T}$ & $\mathrm{~T}$ & $\mathrm{~T}$ & $\mathrm{~T}$ & $\mathrm{~T}$ & $\mathrm{~T}$ & $\mathrm{~T}$ & $\mathrm{~T}$ & $\mathrm{~T}$ & $\mathrm{~T}$ & $0 \%$ \\
\hline 10 & $\mathrm{~T}$ & $\mathrm{~T}$ & $\mathrm{~T}$ & $\mathrm{~T}$ & $\mathrm{~T}$ & $\mathrm{~T}$ & $\mathrm{~T}$ & $\mathrm{~T}$ & $\mathrm{~T}$ & $\mathrm{~T}$ & $0 \%$ \\
\hline
\end{tabular}

Pada Tabel 1 bisa lihat pada jarang 1 meter sampai 35 meter masih bisa di nyalakan dan untuk jarak 50 meter sampai 70 meter sudah tidak bisa di nyalakan,dan bisa di tarik kesimpulan bahwa lampu bisa di kontrol dalam jarak maksimal 35 meter dikarenakan jaringannya sudah ofline jadi terputus.

\subsection{Pengujian Sensor PIR}

Pengujian ini mengukur seberapa jauh sensor PIR dapat bekerja untuk mendeteksi gerakan. Dilakukan percobaan pada setiap jarak yang telah ditentukan untuk menguji sensitivitas sensor PIR. Pada Tabel 3 adalah hasil pengujian dari sensitivitas sensor PIR untuk mendeteksi suatu obyek berdasarkan jarak. 
Tabel 2. Pengukuran Jarak Jangkauan Sensor PIR

\begin{tabular}{|c|c|c|}
\hline Jarak (Meter) & On & Off \\
\hline 1 & YA & YA \\
\hline 5 & YA & YA \\
\hline 7 & YA & YA \\
\hline 10 & YA & YA \\
\hline 15 & YA & YA \\
\hline 20 & YA & YA \\
\hline 35 & YA & YA \\
\hline 50 & TIDAK & TIDAK \\
\hline 75 & TIDAK & TIDAK \\
\hline
\end{tabular}

Ket :

$\mathrm{S}=$ Sukses Mendeteksi Objek

$\mathrm{T}=$ Tidak Bisa Mendeteksi Objek

Jadi pada tabel percobaan 4.6 dilakukan 10 percobaan diatas dapat ditarik kesimpulan pada jarak 1 sampai 6 meter terdeteksi dengan baik,dan pada jarak 7 meter hanya $70 \%$ yang terdeteksi, sedangkan pada jarak 8 meter hanya 50\% yang terdeteksi dan selanjutnya pada meter 9 dan 10 tidak terdeteksi sama sekali atau $0 \%$.

\subsection{Pengujian Sensor LM35}

Pengujian ini mengukur kondisi suhu pada ruangan selama 10 (sepuluh) kali percobaan.

Tabel 3. Uji Coba Sensor LM35

\begin{tabular}{|l|l|}
\hline Menit Ke & Suhu ${ }^{0} \mathrm{C}$ \\
\hline 1 & 22 \\
\hline 2 & 23 \\
\hline 3 & 22 \\
\hline 4 & 23 \\
\hline 5 & 22 \\
\hline 6 & 22 \\
\hline 7 & 23 \\
\hline 8 & 22 \\
\hline 9 & 22 \\
\hline 10 & 23 \\
\hline
\end{tabular}

Dari percobaan di atas dapat di lihat menit ke 1 sampai menit ke 10 terhitung suhu dalam ruangan adalah $22^{\circ} \mathrm{C}$ dan $23^{\circ} \mathrm{C}$.

\subsection{Uji Coba Sensor MQ2}

Uji coba ini bertujuan untuk mengukur ada atau tidaknya kebocoran pada ruangan dan terdeteksi oleh sensor yang kemudian dikirim ke aplikasi blynk.
Tabel 4. Hasil Uji Coba Sensor MQ2

\begin{tabular}{|c|c|}
\hline $\begin{array}{c}\text { Peberian } \\
\text { Gas }\end{array}$ & $\begin{array}{c}\text { Hasil Notifikasi } \\
\text { Aplikasi Blynk }\end{array}$ \\
\hline Tidak Diberi & Tidak Berbunyi \\
\hline Diberi & Bunyi \\
\hline
\end{tabular}

\section{PENUTUP}

\subsection{Kesimpulan}

Smart Home dengan Modul NodeMCU ESP8266 berbasis Internet of Things (IoT) ini dapat diimplementasikan untuk mengontrol beberapa kinerja elektronik rumah diantaranya yaitu pada kontrol lampu, monitoring suhu, early warning system kebocoran gas, dan sistem keamanan rumah sesuai dengan apa yang diharapkan asalkan koneksi internet (WiFi) dalam keadaan stabil sehingga meminimalisir terjadinya error. Berdasarkan hasil pengujian, sensor PIR dapat mendeteksi gerakan pada jangkauan jarak 1 sampai 9 meter,tapi yang berhasil $100 \%$ hanya sampai 5 meter,pada meter ke 6 hanya 70\%,dan meter ke 7 dan 8 hanya 50\%. Berdasarkan hasil uji coba sensor suhu LM35, didapatkan hasil yang cukup baik pada beberapa percobaan dibandingkan dengan aplikasi yang ada di aplikasi smartphone. Aplikasi Blynk perlu terkoneksi ke jaringan internet untuk dapat mengirimkan notifikasi jika ada gerakan yang terdeteksi oleh sensor PIR. Berdasarkan pengujian, waktu yang di butuhkan untuk mengirim dan menerima notifikasi di smartphone user melalui aplikasi blynk berkisar pada 3-6 detik. Walaupun demikian waktu dapat di pengaruhi oleh konektifitas jaringan internet. Menghidupkan lampu dan mematikan lampu dengan sangat mudah bisa di lakukan lewat aplikasi blynk pada smartphone, dengan jarak paling jauh 35 meter, dengan delay waktu on dan off berkisar antara 0,5 sampai 1 detik jadi lumayan cepat, hampir tidak ada delay waktu /jeda.

\subsection{Saran}

Dengan menggunakan alat ini kita dapat mengontrol dan monitoring rumah hanya dari smartphone dengan aplikasi blynk. Pada uji coba sensor MQ2 dapat mendeteksi dengan baik. Smart Home Dengan menggunakan aplikasi Blynk kita dapat dengan mudah mengetahui suhu ruangan, Smart Home ini terjamin keamanannya karena bisa mendeteksi gerakan oleh sensor PIR dan mendeteksi gas bocor oleh sensor MQ2. Adapun uji coba menghitung tegangan pada relay saat lampu hidup dan mati,dan didapatkan hasil tegangan relay 
Jurnal Rekayasa Teknologi Nusa Putra. Vol. 7, No. 1, September 2020: Hal 1- 7

lebih besar saat lampu mati,dikarnakan saat lampu hidup tegangan terbagi dan akan lebih kecil.dan itupun sama halnya untuk sensor PIR

\section{DAFTAR PUSTAKA}

[1] N. H.L. Dewi, "Prototype Smart Home dengan Modul Nodemcu ESP8266 Berbasis Internet of Things (IoT)".

[2] F. Masykur, "Aplikasi rumah pintar (smart home) pengendali peralatan elektronik rumah tangga berbasis web", Desember 2016.

[3] Z. Abidin, "Sistem keamanan dan monitoring rumah pintar secara online menggunakan perangkat mobile", Desember 2015.

[4] R. Permana, "Perancangan system ke amanan dan system kontrol smart home Berbasis internet of things", Desember 2017.

[5] Z. Abidin, "Sistem keamanan dan monitoring rumah pintar secara online menggunakan perangkat mobile, 2014.

[6] Juwariyah, "Perancangan Sistem Deteksi Dini Pencegah Kebakaran Rumah Berbasis ESP8266 dan Blynk", Juni 2018. 